\title{
Reações químicas na cozinha: o uso do Google Sala de Aula NA REALIZAÇÃO DE EXPERIMENTOS INVESTIGATIVOS FUNDAMENTADOS NA TÉCNICA PREDIZER-ObSeRVAR-EXPLICAR
}

CHEMICAL REACTIONS IN THE KITCHEN: THE USE OF GOOGLE CLASSROOM IN THE REALIZATION OF INVESTIGATIVE EXPERIMENTS BASED ON THE PREDICT-OBSERVEEXPLAIN TECHNIQUE

REACCIONES QUÍMICAS EN LA COCINA: EL USO DE GOOGLE CLASSROOM EN LA REALIZACIÓN DE EXPERIMENTOS DE INVESTIGACIÓN BASADOS EN LA TÉCNICA PREDECIR-OBSERVAR-EXPLICAR

\section{Rafael da Costa Brito \\ (iD) 9 \\ Mestre em Química (UFRGS) \\ rcbcosta@gmail.com}

\section{Andrey de Lima Czolpinski (iD) 9}

Graduado em Licenciatura em Química (UFRGS)

czolpinskiandrey@gmail.com

\section{Alef Vaz (iD) 9 \\ Graduando em Química (UFRGS) alef.1.vaz@gmail.com}

\section{Daniele Trajano Raupp (iD) 9}

Doutora em Educação em Ciências (UFRGS)

Docente no Instituto de Química (UFRGS)

Docente do Programa de Pós-

Graduação de Educação em

Ciências (UFRGS)

daniele.raupp@ufrgs.br

\begin{abstract}
Resumo
Este trabalho objetiva relatar a experiência da implementação de uma sequência didática (SD) sobre reações químicas inorgânicas de forma remota em função da pandemia do novo coronavírus. O estudo de caso com abordagem qualitativa foi realizado com duas turmas do Ensino Médio de uma escola privada de Porto Alegre/RS durante o Estágio de Docência. A SD, elaborada conforme os pressupostos de Zabala, objetivou minimizar dificuldades de compreensão conceitual, potencializadas pelo ensino remoto. O Google Sala de Aula foi utilizado para organização das atividades experimentais investigativas, com materiais caseiros, com o uso da técnica Predizer-ObservarExplicar. A metodologia de análise dos dados foi a Análise de Conteúdo. Os resultados indicam que a SD facilitou a construção conceitual, gerou um engajamento progressivo e um notável entusiasmo relacionado às aulas remotas. Como conclusão, a utilização da SD demonstra potencial para aplicação em diferentes contextos de ensino, com diferentes experimentos para abordagem de diversos conceitos.
\end{abstract}

Palavras-chave: Ambientes Virtuais de Aprendizagem. Ensino remoto. Experimentos Caseiros. Ensino de Química.

Recebido em: 23 de julho de 2021.

Aprovado em: 14 de dezembro de 2021.

Como citar esse artigo (ABNT):

BRITO, Rafael da Costa et al. Reações químicas na cozinha: o uso do Google Sala de Aula na realização de experimentos investigativos fundamentados na técnica Predizer-ObservarExplicar. Revista Prática Docente, v. 6, n. 3, e098. 2021. http://doi.org/10.23926/RPD.2021.v6.n3.e098.id1273 


\section{Abstract}

This work aims to report the experience of implementing a didactic sequence (DS) on inorganic chemical reactions remotely, due to the COVID sanitary restrictions. The case study with a qualitative approach was carried out with two high school classes from a private school in Porto Alegre/RS, during the Teaching Internship. The DS, elaborated according to Zabala's assumptions, aimed to minimize difficulties in conceptual understanding, potentially enhanced by remote learning. Google Classroom was used to organize the investigative experimental activities, with homemade materials, using the Predict-ObserveExplain technique. The data analysis methodology was Content Analysis. The results indicate that DS facilitated the conceptual construction, generated a progressive engagement and remarkable enthusiasm even with remote classes. In conclusion, the use of DS shows potential for application in different teaching contexts, with different experiments to approach different concepts.

Keywords: Virtual Environments for Learning. Remote Teaching. At-Home Experiments. Teaching Chemistry.

\section{Resumen}

Este trabajo tiene como objetivo reportar la experiencia de implementar una secuencia didáctica (SD) sobre reacciones químicas inorgánicas de forma remota, como consecuencia de la nueva pandemia de coronavirus. El estudio de caso con enfoque cualitativo se realizó con dos aulas de bachillerato de una escuela privada en Porto Alegre/RS durante la Práctica Docente. El DS, elaborado de acuerdo con los supuestos de Zabala, tenía como objetivo minimizar las dificultades en la comprensión conceptual, mejorada por el aprendizaje remoto. Se utilizó Google Classroom para organizar las actividades experimentales de investigación, con materiales caseros, utilizando la técnica Predict-Observe-Explain. La metodología de análisis de datos fue Análisis de contenido. Los resultados indican que SD facilitó la construcción conceptual, generó un compromiso progresivo y un notable entusiasmo relacionado con las clases remotas. En conclusión, el uso de SD muestra potencial para su aplicación en diferentes contextos de enseñanza, con diferentes experimentos para abordar diferentes conceptos.

Palabras clave: Entornos Virtuales de Aprendizaje. Enseñanza Remota. Experimentos Caseros. Enseñanza de la Química. 


\section{INTRODUÇÃO}

Instituições de ensino ao redor do mundo foram forçadas a adotar modalidades de ensino alternativas ao modelo presencial devido à pandemia do novo coronavírus. Essa transição ocorreu de forma muito rápida e inesperada, demandando a necessidade de múltiplas estratégias para o ensino (DIETRICH et al., 2020). A comunidade acadêmica teve que garantir a continuidade pedagógica a fim de fornecer aos seus alunos o conhecimento necessário para seu sucesso na aprendizagem (DANJOU, 2020).

Em outros contextos de interrupção das atividades de ensino, como desastres naturais, doenças, ataques terroristas e outras situações já vivenciadas nos mais diversos países, constatase que a maioria dos alunos luta para encontrar um ambiente pacífico de aprendizagem na sala de aula (POTGIETER et al., 2019). Nesse cenário incomum, os alunos costumam confiar em seus professores para proporcionar um ambiente de aprendizado envolvente que possa ajudálos a superar essas lutas (TIGAA; SONAWANE, 2020).

Objetivando diminuir os efeitos da impossibilidade de usar os métodos de ensino tradicionalmente utilizados nas aulas presenciais, que fornecem melhor interação professoraluno (JENSEN; PRICE, ROXÅ, 2020), os Ambientes Virtuais de Aprendizagem (AVAs) têm como potencial a flexibilidade na aprendizagem por meio de uma variedade de plataformas para estudar e aprender (HOLME, 2020). De fato, as Tecnologias de Informação e Comunicação (TICs) tiveram seu uso potencializado durante esse período atípico, sendo utilizadas como ferramentas de ensino e de estudo.

Tais tecnologias contribuem com o processo de ensino e a organização das práticas pedagógicas (YAMAGUCHI, 2021), principalmente os softwares conhecidos como AVAs, e seus recursos, os quais têm sido amplamente utilizados. Segundo Vasconcellos, Tamariz e Batista (2019), os recursos variam de acordo com o AVA, podendo ser fóruns, quadros de avisos, disponibilização de materiais, organização de atividades avaliativas, entre outros.

Ensinar e aprender por meio do uso dessas tecnologias é uma prática comum em países desenvolvidos, mas, em muitos lugares, continua sendo um desafio para estudantes e professores. Isso se dá devido a múltiplos fatores como, por exemplo, o não acesso a software ou hardware, falta de internet, ou de internet de alta velocidade, fonte de alimentação não confiável, restrições financeiras e falta de treinamento dos educadores (CRAWFORD et al., 2020). Por isso, a transição das atividades presenciais para as atividades totalmente on-line ou remotas causou inúmeras perturbações, em especial para áreas como a química. 
Dado o caráter experimental das ciências, tanto em sua prática quanto em seu ensino, em se tratando especificamente da realização de atividades experimentais, os professores de química reinventaram suas práticas pedagógicas ao conduzir, junto de seus estudantes, experimentos de laboratório que podem ser realizados com segurança em casa (NGUYEN; KEUSEMAN, 2020). Tais experimentos podem contribuir para o engajamento dos estudantes e a percepção de como a química faz parte de nossas vidas diárias (HAYES et al., 2020).

Diante desse contexto, nosso trabalho objetiva relatar a implementação de uma sequência didática (SD) sobre reações químicas inorgânicas realizada de forma remota em um AVA. A SD foi elaborada e aplicada, durante o Estágio de Docência, por dois licenciandos em química que, em função da pandemia do novo coronavírus, realizaram seu estágio de forma $100 \%$ remota. Buscando superar um desafio - que originou a seguinte pergunta de pesquisa: "Que estratégia utilizar para abordar remotamente o conceito de reações químicas com estudantes do Ensino Médio?", - foi elaborada uma SD tendo como principal proposta metodológica o uso da técnica Predizer-Observar-Explicar (POE) para a execução, de forma autônoma pelos estudantes, de duas atividades experimentais abordando o conteúdo de reações químicas. O Google Sala de Aula e seus recursos foram utilizados como AVAs para a organização de experimentos caseiros. ${ }^{1}$ Tais atividades foram realizadas na cozinha da casa dos estudantes com materiais seguros e de fácil acesso.

\section{O ENSINO DE REAÇÕES QUÍMICAS E OS EXPERIMENTOS CASEIROS}

O estudo das reações é fundamental na química. Meneses e Nuñez (2018) argumentam que, para compreender tal conceito, é necessário dominar outros e integrar parâmetros quantitativos, termodinâmicos, cinéticos e de equilíbrio. Sem essa noção integrada para o entendimento de uma reação química, caracterizada por ser um sistema complexo, o conhecimento é construído de modo fragmentado e descontextualizado. Todavia, as problemáticas a respeito desse assunto são várias e de diversas origens. A necessidade da transição entre níveis de representação (JOHNSTONE, 1991) macroscópico, microscópico e simbólico e as concepções alternativas também estão relacionadas às dificuldades de aprendizagem deste tópico.

\footnotetext{
1 Adotamos, neste estudo, os termos "experimentos caseiros" e "materiais caseiros" em detrimento de "alternativos" em função de as atividades terem sido planejadas e executadas durante o período da pandemia nos domicílios dos estudantes. O planejamento levou em conta a organização de experimentos com insumos como produtos de limpeza e ingredientes culinários para que os alunos não precisassem comprar nenhum insumo.
} 
Uma estratégia comumente empregada no ensino de reações é a experimentação, uma vez que contribui para o desenvolvimento de capacidades como: verificação de hipóteses, compreensão e modelagem de problemas, formulação de hipóteses e elaboração de resultados. Portanto, a experimentação é um elemento fundamental no aprendizado quando se dispõe das condições adequadas (TAKAHASHI; CARDOSO, 2011).

Durante a pandemia do novo coronavírus, na impossibilidade de utilização de um laboratório de química, ou até mesmo do uso de experimentos demonstrativos em sala de aula, o desafio foi substituir ou adequar essas aulas. Al-Soufi, Carrazana-Garcia e Novo (2020) relatam, em seu artigo "When the kitchen turns into a physical chemistry lab", que o primeiro impulso durante o início do lockdown na Espanha foi o de utilizar simulações ou cálculo no lugar de atividades experimentais. No entanto, decidiram usar experimentos realizados em casa para não privar os alunos de tal experiência.

Bell (2014) destaca que a maioria dos alunos não reconhece que nosso primeiro laboratório é a cozinha. Os vários ingredientes culinários são reagentes e os inúmeros utensílios de cozinha são os equipamentos de laboratório. De fato, existe uma vasta gama de experimentos que implementamos diariamente, sem perceber a noção da profundidade das reações químicas em nosso dia a dia. No contexto do atual cenário pandêmico, a utilização da cozinha para simular um laboratório pode ser uma estratégia para a realização de experimentos, uma vez que o aspecto principal são as perguntas "como" e "para quê" as atividades são realizadas, incluindo a definição dos objetivos a serem alcançados e, por fim, a clareza do papel da experimentação na aprendizagem (PUGGIAN; MORAES; LOPES, 2016).

Esses experimentos caseiros podem ser otimizados por meio de uma estratégia de experimentação investigativa, que tem o intuito de envolver os estudantes de forma mais efetiva no processo de aprendizagem (SUART; MARCONDES, 2009). Considerando que ela é caracterizada pela resolução de um problema por meio da experimentação, é necessário o envolvimento de reflexões, discussões e explicações, e não apenas observação. Essa participação ativa contribui para o desenvolvimento de habilidades importantes no processo de aprendizagem, como, por exemplo, a argumentação (MENEZES; FARIAS, 2020), a capacidade de resolução de problemas e a construção do próprio conhecimento (FERREIRA; HARTWIG; OLIVEIRA, 2010, p. 101).

A experimentação investigativa intenciona superar a visão mecânica das aulas experimentais, que seguem roteiros de maneira sequencial e sem uma aprendizagem 
significativa, já que se apresenta uma situação problema para instigar os estudantes a buscar uma solução (MONTEIRO et al., 2019). Por isso, o estudante deve estar engajado intelectualmente na atividade, e não apenas realizar um trabalho de manipulação de vidrarias (SOUZA; AKAHOSHI; MARCONDES, 2013). Nesse sentido, o uso da técnica POE pode contribuir para a organização didática das atividades experimentais investigativas.

\section{A téCNiCa Predizer-ObServar-ExPlicar}

A técnica POE, desenvolvida por Richard White e Richard Gunstone (1992), foi baseada na estratégia Demonstrar-Observar-Explicar (D. O. E.), criada em 1979 por Audrey B. Champagne. Inicialmente utilizada como teste para a avaliação prévia dos conhecimentos, a técnica objetiva que os alunos externalizem de forma eficiente suas ideias por meio de predições do resultado de uma demonstração - ou da execução de determinada atividade -, discutindo as razões de suas previsões, observando a execução e, finalmente, explicando quaisquer discrepâncias entre suas predições e observações (KEARNEY, 2004).

Dessa forma, além de permitir a identificação dos conhecimentos prévios, é possível conhecer os processos de pensamento dos alunos e, assim, pontuar as concepções equivocadas acerca da ciência de forma a buscar soluções sustentáveis para que os alunos possam superálas (KIBIRIGE; OSODO; TLALA, 2014). Desde então, essa técnica tem sido empregada mundialmente na condução de atividades experimentais para o ensino de diferentes áreas (LIEW; TREAGUST, 1995; BILEN; ÖZEL; KÖSE, 2016), atividades mediadas por computador (PIEPER; ANDRADE NETO, 2015) e até análise de vídeos (GAGNO JÚNIOR; BROZEGUINI, 2020). Por meio da observação e da explicação, o caráter investigativo da POE permite que os alunos sejam estimulados a assumir uma postura ativa. Tal fato desencadeia uma mudança conceitual por parte do aluno e também melhora a sua compreensão (NASRI, 2020).

Resumidamente, as três etapas são: a) Predizer - são realizadas predições a partir das quais o aluno pressupõe possíveis acontecimentos que serão desencadeados após o início da realização de determinada atividade, sendo requisitado que o raciocínio seja explicado; b) Observar - durante a etapa de observação do fenômeno, é sugerido fazer anotações sobre o que está sendo observado; c) Explicar - realiza-se uma comparação entre a predição e o que, de fato, fora observado. Caso as previsões e observações dos alunos apresentem inconsistências entre si, pode ocorrer um conflito cognitivo que pode induzir uma mudança conceitual (WHITE; GUNSTONE, 1992; CINICI; DEMIR, 2013). 


\section{Metodologia}

A elaboração da SD, para esse estudo de caso qualitativo, foi baseada nos pressupostos adotados por Zabala, que conceitua uma SD como um "conjunto de atividades ordenadas, estruturadas e articuladas para a realização de certos objetivos educacionais que têm um princípio e um fim conhecidos tanto pelo professor como pelos alunos" (ZABALA, 1998, p. 18).

A SD elaborada segundo essa perspectiva tem um caráter processual, envolvendo as fases de planejamento, aplicação e avaliação. Dessa forma, as etapas de elaboração incluíram reuniões entre os licenciados e a professora orientadora para a organização das atividades da SD, que foi implementada em duas turmas de primeira série do Ensino Médio, totalizando 62 estudantes, em uma escola da rede privada na região metropolitana de Porto Alegre, no período de novembro de 2020, na disciplina de Química, com carga horária de 3h/aula semanais. A SD contou com o uso das ferramentas disponíveis no Google Sala de Aula. A execução dos experimentos sobre reações químicas inorgânicas com a técnica POE, com materiais caseiros, teve dois momentos, que são descritos a seguir.

\section{1. $1^{\circ}$ MOMENTO - PREDIZER}

Na primeira aula, via Google Meet, solicitou-se que os estudantes preenchessem um formulário on-line, via Google Forms, em que deveriam realizar predições sobre que ocorreria ao misturar os ingredientes, ou seja, explicar o fenômeno com base em seus conhecimentos prévios. Os estudantes foram informados de que tal atividade não seria um teste - pois, dessa forma, cria-se um ambiente de livre expressão.

Solicitou-se, então, que os estudantes respondessem de forma individual às seguintes questões sobre os experimentos:

a) Experimento 1: em uma garrafa PET de $600 \mathrm{~mL}$, são colocados $300 \mathrm{~mL}$ de vinagre (ácido acético) e é adicionada uma colher de bicarbonato de sódio $\left(\mathrm{NaHCO}_{3}\right)$. Logo em seguida, um balão é colocado no gargalo da garrafa PET. O que deverá ocorrer?

b) Experimento 2: utiliza-se novamente uma garrafa PET de $600 \mathrm{~mL}$, sendo adicionados cerca de $300 \mathrm{~mL}$ de água e uma ponta de colher de chá de bicarbonato de sódio $\left(\mathrm{NaHCO}_{3}\right)$. Ocorre a mistura da solução até a dissolução total do bicarbonato. Posteriormente, algumas gotas de uma solução indicadora de repolho roxo são adicionadas a essa mistura. Por fim, acende-se um fósforo no gargalo da garrafa com o intuito de que a fumaça seja concentrada dentro da garrafa, cobrindo- 
se o gargalo rapidamente. Com a garrafa tampada, agita-se o conteúdo. O que ocorre ao adicionar o indicador e, posteriormente, com a presença da fumaça?

\section{2. $2^{\circ}$ MOMENTO-OBSERVAR E EXPLICAR}

Antes da realização da etapa de observação, materiais de estudo foram disponibilizados no Google Sala de Aula. Os referidos materiais eram vídeos de reações químicas com, no máximo, 1 minuto de duração, em que era abordado cada um dos tipos de reações químicas inorgânicas envolvidas (síntese, decomposição, simples troca e dupla troca). Esses vídeos tinham como objetivo diminuir a lacuna presente na realização do experimento de forma autônoma devido ao momento de ensino remoto, fornecendo, assim, referências visuais de reações químicas para que se pudesse criar um referencial visual do que deveria ser observado (uma vez que as reações escolhidas para a atividade envolvem transformações visuais facilmente observáveis).

Os alunos foram orientados a assistir a esses vídeos e a ler atentamente os roteiros dos experimentos - os quais foram disponibilizados via Google Sala de Aula. A execução dos experimentos para observação das reações deveria ser filmada e o vídeo, postado como resposta à atividade criada na plataforma. O roteiro levou em conta o uso de ingredientes culinários, bem como de utensílios domésticos comuns do cotidiano para que, dessa forma, os estudantes fizessem as medições de volume.

Destacou-se que os experimentos apresentavam uma abordagem qualitativa e o foco era a observação da reação. Intencionalmente, foram selecionados experimentos com características macroscópicas facilmente identificáveis. O Experimento 1 foi uma reação de dupla-troca entre o bicarbonato de sódio e o ácido acético $\left(\mathrm{NaHCO}_{3}(\mathrm{~s})+\mathrm{CH}_{3} \mathrm{COOH}(\mathrm{aq}) \rightarrow\right.$ $\mathrm{CH}_{3} \mathrm{COONa}(\mathrm{aq})+\mathrm{H}_{2} \mathrm{CO}_{3}(\mathrm{aq})$ ) e foi seguido pela decomposição do ácido carbônico em dióxido de carbono e água $\left(\mathrm{H}_{2} \mathrm{CO}_{3}(\mathrm{aq}) \rightarrow \mathrm{H}_{2} \mathrm{O}(\mathrm{l})+\mathrm{CO}_{2}(\mathrm{~g})\right)$. A Figura 1 contém a descrição do experimento denominado "Balão que enche sozinho".

Figura 1 - Roteiro para o Experimento 1

Experimento 1.Materiais necessários são vinagre; bicarbonato de sódio; garrafa PET transparente sem tampa (600 mL); balão inflável; uma xícara; uma colher de sopa e um funil. Metodologia : $1^{\circ}$ passo: Com o auxílio do funil adicione meia xícara de vinagre na garrafa PET. $2^{\circ}$ passo: Com o auxílio do funil adicione uma colher de sopa de bicarbonato de sódio dentro do balão. $3^{\circ}$ passo: cubra a boca da garrafa PET com a boca do balão, como demonstrado na imagem. $4^{\circ}$ passo: Despeje o conteúdo do balão dentro da garrafa PET. $5^{\circ}$ passo: Observe o que acontece.

Fonte: Dados da experimentação (2021). 
No Experimento 2, ocorre a reação de dupla-troca entre uma solução de bicarbonato de sódio e a fumaça de um palito de fósforo na presença do indicador advindo do repolho roxo $\left(2 \mathrm{NaHCO}_{3}(\mathrm{~s})+\mathrm{SO}_{2}(\mathrm{~g}) \rightarrow \mathrm{Na}_{2} \mathrm{~S}+\mathrm{H}_{2} \mathrm{O}(\mathrm{l})+\mathrm{CO}_{2}(\mathrm{~g})\right)$. O roteiro do experimento denominado "Neutralização de bicarbonato de sódio com a fumaça do palito de fósforo" é apresentado na Figura 2.

Figura 2 - Roteiro para o Experimento 2

Experimento 2. Materiais necessários: Bicarbonato de sódio; água; álcool de limpeza; repolho roxo; palitos de fósforo; uma colher de chá; uma xícara; um copo grande; uma garrafa PET $(600 \mathrm{~mL})$ transparente com tampa; um funil; um conta-gotas. Metodologia. $1^{\circ}$ passo: Em um copo grande, adicione o equivalente a meia garrafa PET de água (300 $\mathrm{mL}$ ) e $1 / 4$ de colher de chá de bicarbonato de sódio, mexa bem para dissolver. $2^{\circ}$ passo: Preparação do indicador - Primeiro colocar no liquidificador $1 / 3$ do repolho roxo e bater com $200 \mathrm{ml}$ de água. Depois coar a mistura entre o repolho e a água e separar em um recipiente. Essa solução servirá como um indicador de reações ácido-base. $3^{\circ}$ passo: Com o auxílio de um funil, coloque um pouco - cerca de 3 dedos da solução preparada no $1^{\circ}$ passo (solução de bicarbonato de sódio) na garrafa PET e, em seguida, com o auxílio de um conta-gotas adicione algumas gotas da solução preparada no $2^{\circ}$ passo (solução de indicador) na garrafa PET. Você deverá ver a solução ficar levemente azulada. $4^{\circ}$ passo: Acenda o palito de fósforo e segure-o aceso dentro da garrafa PET, para que concentre um pouco de fumaça dentro da garrafa, e rapidamente tampe a garrafa. Agite vigorosamente.

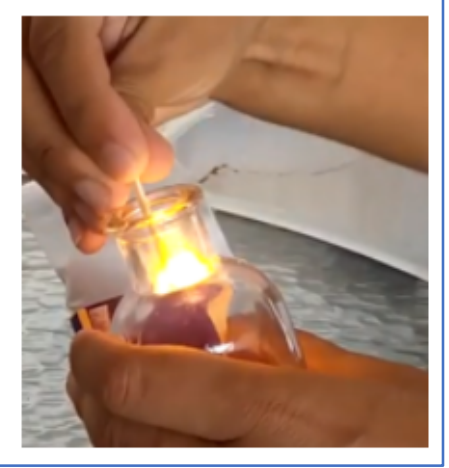

Fonte: Dados da experimentação (2021).

$\mathrm{Na}$ elaboração do relatório individual, solicitou-se que cinco perguntas fossem respondidas: 1) Classifique e equacione as reações de acordo com o que foi visto em aula (síntese, decomposição, deslocamento ou dupla-troca); 2) Relate o que foi observado (desprendimento de gás, formação de precipitado, etc.), levando em consideração os vídeos anteriores, os quais foram usados como base (postados no Classroom); 3) Retomando o formulário do Google Forms (respondido na aula anterior), os experimentos seguiram conforme você havia imaginado? 4) Anexe como resposta registros das experiências - podem ser fotos ou vídeos; 5) Em suas palavras, o que você achou da dificuldade relacionada à montagem dos experimentos e da resposta às questões? Já havia realizado outras experiências de ciências da natureza em casa?

Destaca-se que a SD proposta, utilizando o Google Sala de Aula como AVA, pode ser empregada em qualquer modalidade de ensino, seja pela necessidade de utilizar a experimentação em situações em que não é possível de forma presencial, seja nos casos em que 
há limitações para a realização de experimentos convencionais, na hipótese de ausência de laboratórios e insumos ou, ainda, quando o foco é evitar a produção de resíduos químicos.

\section{RESUlTAdOS E DisCUSSÃO}

Os dados coletados foram analisados segundo os pressupostos da análise de conteúdo de Bardin (2016), que compreende pré-análise, exploração do material e tratamento dos resultados. Para a codificação, adotou-se como regra de enumeração a frequência de aparição e utilizou-se, no tratamento dos resultados, o método das categorias de acordo com as etapas propostas por Laville e Dionne (1999): 1) recorte de conteúdos; 2) definiçãa das categorias; 3 ) categorização final.

Sobre a etapa "predizer", após pré-análise e exploração do material, foi possível realizar a classificação das respostas em quatro categorias: a) respostas em nível macroscópico: nessa categoria, foram alocados os estudantes que usaram apenas o nível de representação macroscópico para tentar explicar o que ocorreria nas reações; b) menção à ideia de reação: as respostas que usavam a palavra "reação" ou algum sinônimo como argumentação; c) descrição em nível macroscópico e atômico: respostas em que os estudantes explicaram o que aconteceria ao ser criado o sistema de análise de forma visual e argumentaram usando a ideia de rearranjo atômico; d) respostas com incoerências: qualquer tipo de concepção alternativa aos experimentos foi classificado nesse critério.

O Quadro 1 apresenta exemplos de respostas dos estudantes que delinearam a criação da categorização final.

\begin{tabular}{|l|l|l|}
\hline \multicolumn{1}{|c|}{ Quadro 1 - Categorias e exemplos das respostas dos estudantes } \\
\hline $\begin{array}{l}\text { Respostas em nível } \\
\text { macroscópico }\end{array}$ & \multicolumn{1}{|c|}{ Experimento 1 } & \multicolumn{1}{c|}{ Experimento 2 } \\
\hline "O balão enche." & "Muda de cor." \\
Menção à ideia de reação & $\begin{array}{l}\text { "Acho que o balão irá encher por } \\
\text { causa da reação entre o bicarbonato e e } \\
\text { o vinagre." }\end{array}$ & $\begin{array}{l}\text { "Esse é um tipo de reação de dupla } \\
\text { troca, ou seja, quando duas } \\
\text { substâncias compostas reagem entre } \\
\text { si, trocando seus componentes e dando } \\
\text { origem a duas novas substâncias } \\
\text { compostas." }\end{array}$ \\
\hline $\begin{array}{l}\text { Descrição em nível } \\
\text { macroscópico e atômico }\end{array}$ & $\begin{array}{l}\text { "A mistura do vinagre com o } \\
\text { bicarbonato de sódio gera um } \\
\text { que depois vai virar dióxido de } \\
\text { carbono." }\end{array}$ & $\begin{array}{l}\text { "Ao misturar o bicarbonato, a solução } \\
\text { tornou-se básica (tem caráter básico } \\
\text { em solução aquosa), então o indicador } \\
\text { ficou com a cor correspondente à } \\
\text { base. Eu acho que, com a presença da } \\
\text { fumaça, o indicador muda de cor." }\end{array}$ \\
\hline $\begin{array}{l}\text { Respostas com } \\
\text { incoerências }\end{array}$ & $\begin{array}{l}\text { "Fermentação.” } \\
\text { "Enche de água." }\end{array}$ \\
\hline
\end{tabular}

Fonte: Dados da experimentação (2021). 
As respostas expõem traços característicos de cada raciocínio por meio da linguagem utilizada, que está cerceada pelo aprendizado que ocorreu ao longo da SD. Os estudantes que conseguiram interpretar as reações e realizar inferências a respeito do que ocorreria em nível macroscópico podem ter se deparado com tais reações em outros momentos e, nesse caso, têm um referencial imagético. A ideia de reação foi um conceito elaborado em conjunto ao longo dos encontros síncronos durante a SD, assim como a relação entre o que ocorre em nível macroscópico e durante a reação química.

As incoerências, por sua vez, fornecem um amplo espectro de respostas que, após a finalização da SD, puderam ser problematizadas em sala de aula do ponto de vista das concepções equivocadas (KIBIRIGE; OSODO; TLALA, 2014). No entanto, esse tipo de análise não faz parte do escopo de pesquisa contemplado por este trabalho. A distribuição de respostas dos estudantes, de acordo com frequência de aparição, em cada uma das categorias, está apresentada nos gráficos na Figura 3. É possível identificar que o Experimento 2 tem maior número de respostas inconsistentes.

Figura 3 - a) Respostas em nível macroscópico; b) Menção à ideia de reação; c) Descrição em nível macroscópico e atômico; d) Respostas com incoerência; e) Não responderam

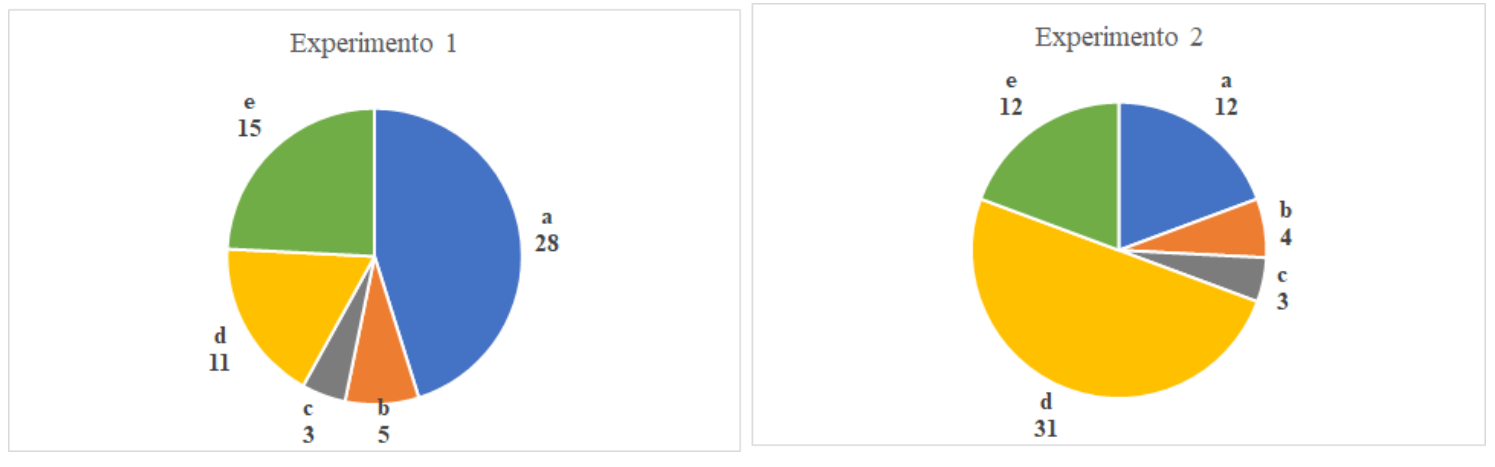

Fonte: Dados da experimentação (2021).

No relatório referente à etapa "observação e explicação", os estudantes apresentaram maior participação no que diz respeito à etapa "predizer" (59 de um total de 62 entregaram um documento criado via Google Documentos com a parte escrita e os registros fotográficos, ou vídeos dos experimentos, juntos na atividade criada anteriormente). Isso indica um crescente interesse dos estudantes na realização dos experimentos. A classificação das reações e o uso do vocabulário adequado foram bem articulados no relatório e as imagens tiveram uma gama diversificada de locais que foram ressignificados para a realização dos experimentos, como pode ser observado nas Figuras 4 e 5. 
Figura 4 - Imagens retiradas dos registros de atividade dos estudantes para o Experimento 1
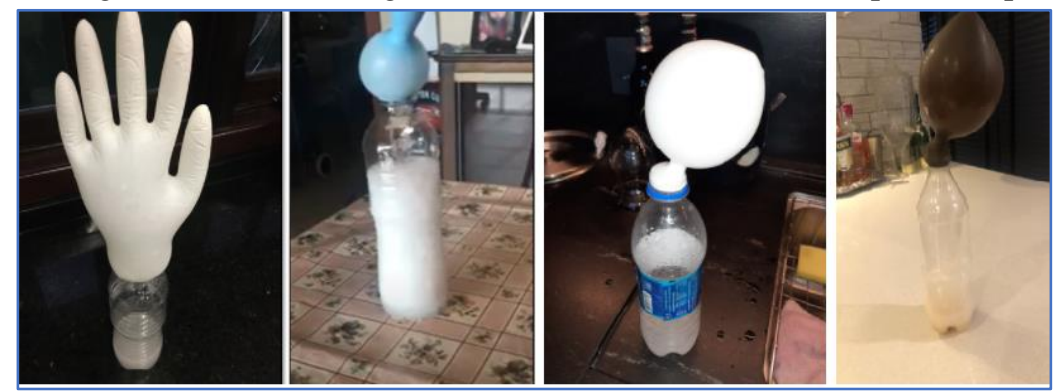

Fonte: Dados da experimentação (2021).

Figura 5 - Imagens retiradas dos registros de atividade dos estudantes para o Experimento 2

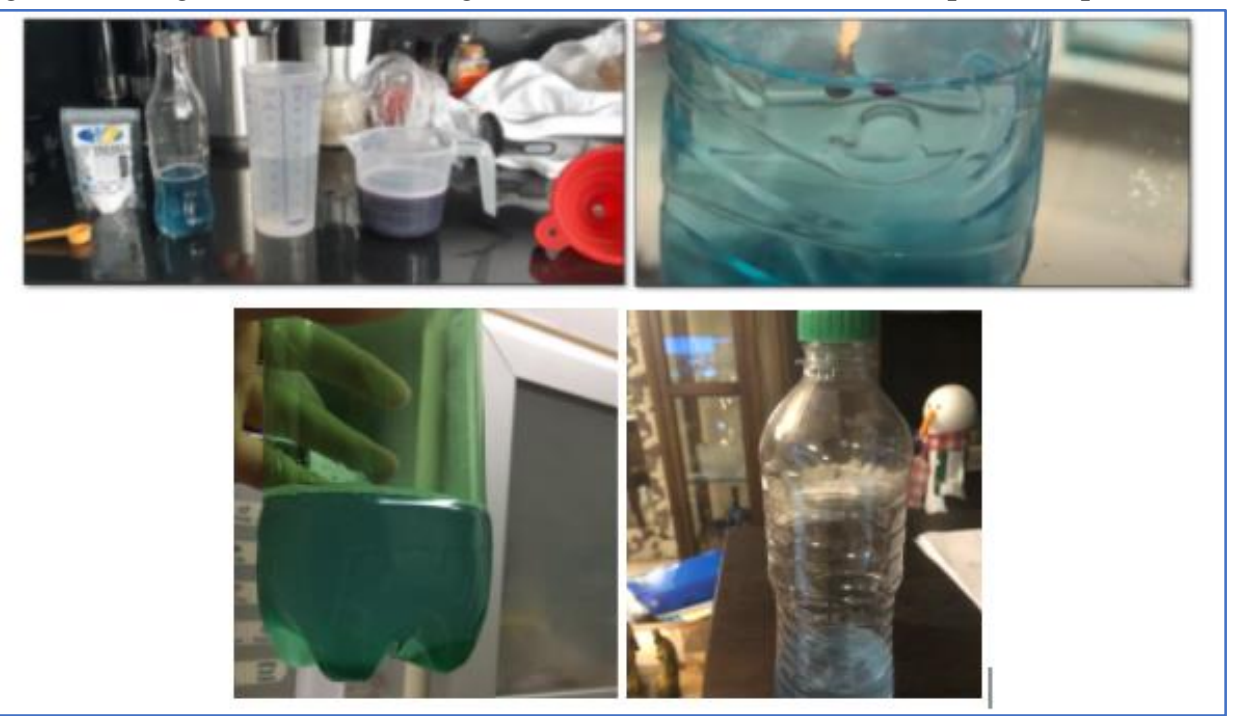

Fonte: Dados da experimentação (2021).

Quanto à dificuldade na realização dos experimentos, os estudantes, de modo geral, não se manifestaram em relação ao procedimento, mas, sim, no que diz respeito ao uso dos aparatos domiciliares (como o liquidificador). Na etapa "predizer", observamos que as respostas apresentaram um direcionamento significativo ao aspecto visual dos experimentos, sem um aprofundamento nas implicações químicas deles.

O uso da técnica POE em um experimento de caráter investigativo pode contribuir para o desenvolvimento de habilidades de raciocínio lógico e argumentação em função do conflito cognitivo identificado entre as etapas "predizer" e "explicar" (CINICI; DEMIR, 2013). A problematização a respeito das incoerências existentes no "predizer" ocorreu de maneira mediada pelo professor durante uma aula síncrona. Também foi realizada, em uma aula síncrona, uma explicação com maior enfoque nos fenômenos observados durante a experimentação, relacionando, assim, as três formas de representação - níveis atomístico, macroscópico e simbólico -, de modo a potencializar a compreensão da transição entre níveis de representação (JOHNSTONE, 1991). 


\section{CONSIDERAÇÕES FINAIS}

Os resultados da aplicação da SD sugerem que os estudantes puderam ressignificar o ambiente domiciliar como um local em que as Ciências da Natureza se fazem presentes, uma vez que houve uma participação crescente nas etapas em que foram desenvolvidos os experimentos. A técnica POE é um tipo de metodologia ativa que proporciona um potente instrumento de análise docente acerca de como está sendo compreendida a atividade experimental e fornece possibilidades de atuação diante das concepções alternativas que possam surgir ao longo do processo de ensino e aprendizagem, independentemente de a SD ser aplicada de forma remota ou presencial.

O uso de materiais caseiros para o desenvolvimento de atividades experimentais pode ser empregado tanto em casos em que as atividades presenciais não são possíveis quanto em situações em que a escola não tem laboratório de ciências com os aparatos e reagentes necessários para a realização de experimentos convencionais - o que é a realidade de muitas escolas brasileiras.

Em síntese, para resolver a problemática de como abordar remotamente o conceito de reações químicas, o uso de experimentos investigativos com materiais caseiros gerou um conflito cognitivo nos estudantes, que, ao se depararem com uma realidade diferente daquela predita por ele mesmo, gerou um desconforto necessário para o aprendizado. A SD implicou um protagonismo do estudante - que foi responsável pela execução e pela investigação da atividade experimental - e, consequentemente, a necessidade de construir novas interfaces a fim de consolidar os saberes desenvolvidos nas aulas, o que resultou em maior autonomia na construção do conhecimento pelos alunos.

\section{REFERÊNCIAS}

AL-SOUFI, Wajih; CARRAZANA-GARCIA, Jorge; NOVO, Mercedes. When the kitchen turns into a physical chemistry lab. Journal of Chemical Education, v. 97, n. 9, p. 3.0903.096, 2020. Disponível em: https://doi.org/10.1021/acs.jchemed.0c00745. Acesso em: 22 jul. 2021.

BARDIN, Laurence. Análise de conteúdo. São Paulo: Edições 70, 2016.

BELL, Patrice. Design of a food chemistry-themed course for nonscience majors. Journal of Chemical Education, v. 91, n. 10, p. 1.631-1.636, 2014. Disponível em: https://doi.org/10.1021/ed4003404. Acesso em: 22 jul. 2021. 
BILEN, Kadir; ÖZEL, Murat; KÖSE, Sacit. Using action research based on the predictobserve-explain strategy for teaching enzymes. Turkish Journal of Education, v. 5, n. 2, p. 72-81, 2016. Disponível em: https://doi.org/10.19128/turje.70576. Acesso em: 22 jul. 2021.

CINICI, Ayhan; DEMIR, Yavuz. Teaching through cooperative POE tasks: a path to conceptual change. The Clearing House: A Journal of Educational Strategies, Issues and Ideas, v. 86, n. 1, p. 1-10, 2013. Disponível em: https://doi.org/10.1080/00098655.2012.712557. Acesso em: 22 jul. 2021.

CRAWFORD, Joseph; BUTLER-HENDERSON, Kerryn; JURGEN, Rudolph; MALKAWI, Bashar. Covid-19: 20 countries' higher education intra-period digital pedagogy responses. Journal of Applied Learning \& Teaching, v. 3, n. 1, p. 1-20, 2020. Disponível em: https://doi.org/10.37074/jalt.2020.3.1.7. Acesso em: 22 jul. 2021.

DANJOU, Pierre-Edouard. Distance teaching of organic chemistry tutorials during the Covid19 pandemic: focus on the use of videos and social media. Journal of Chemical Education, v. 97 , n. 9 , p. 3.168-3.171, 2020. Disponível em: https://doi.org/10.1021/acs.jchemed.0c00485. Acesso em: 22 jul. 2021.

DIETRICH, Nicolas; KENTHESWARAN, Kalyani; AHMADI, Aras, JOHANNE, Teychené. Attempts, successes, and failures of distance learning in the time of Covid-19. Journal of Chemical Education, v. 97, n. 9, 2020. Disponível em: https://doi.org/10.1021/acs.jchemed.0c00717. Acesso em: 22 jul. 2021.

FERREIRA, Luiz Henrique; HARTWIG, Dácio Rodney; OLIVEIRA, Ricardo Castro de. Ensino experimental de química: uma abordagem investigativa contextualizada. Química Nova na Escola, v. 32, n. 2, p. 101-106, 2010. Disponível em: http://qnesc.sbq.org.br/online/qnesc32 2/08-PE-5207.pdf. Acesso em: 12 dez. 2021.

GAGNO JÚNIOR, Fernando; BROZEGUINI, Jardel da Costa. Análise de fenômenos físicos em vídeos: uma proposta de ensino associada ao uso de smartphones em sala de aula.

Pesquisa e Ensino, v. 1, p. e20.2031-e20.2031, 2020. Disponível em: https://doi.org/10.37853/pqe.e202031. Acesso em: 22 jul. 2021.

HAYES, Clare; STOTT, Katherine; LAMB, Katie; HURST, Glenn. "Making every second count": utilizing TikTok and systems thinking to facilitate scientific public engagement and contextualization of chemistry at home. Journal of Chemical Education, v. 97, n. 10, p. 3.858-3.866, 2020. Disponível em: http://doi.org/10.1021/acs.jchemed.0c00511. Acesso em: 22 jul. 2021.

HOLME, Thomas. Chemistry education in times of disruption and the times that lie beyond. Journal of Chemical Education, v. 97, n. 5, p. 1.219-1.220, 2020. Disponível em: http://doi.org/10.1021/acs.jchemed.0c00377. Acesso em: 22 jul. 2021.

JENSEN, Lise; PRICE, Linda; ROXA, Torgny. Seeing through the eyes of a teacher: differences in perceptions of HE teaching in face-to-face and digital contexts. Studies in Higher Education, v. 45, n. 6, p. 1.149-1.159, 2020. Disponível em: https://doi.org/10.1080/03075079.2019.1688280. Acesso em: 22 jul. 2021. 
JOHNSTONE, Alex H. Why is science difficult to learn? Things are seldom what they seem. Journal of Computer Assisted Learning, v. 7, n. 2, p. 75-83, 1991. Disponível em: https://doi.org/10.1111/j.1365-2729.1991.tb00230.x. Acesso em: 22 jul. 2021.

KEARNEY, Matthew. Classroom use of multimedia-supported predict-observe-explain tasks in a social constructivist learning environment. Research in Science Education, v. 34, n. 4, p. 427-453, 2004. Disponível em: http://dx.doi.org/10.1007/s11165-004-8795-y. Acesso em: 22 jul. 2021.

KIBIRIGE, Israel; OSODO, Joseph; TLALA, Kedibone Magdeline. The effect of predictobserve-explain strategy on learners' misconceptions about dissolved salts. Mediterranean Journal of Social Sciences, v. 5, n. 4, p. 300-300, 2014. Disponível em: http://dx.doi.org/10.5901/mjss.2014.v5n4p300. Acesso em: 22 jul. 2021.

LAVILLE, Christian; DIONNE, Jean. A construção do saber. Belo Horizonte: UFMG, 1999.

LIEW, Chong Wang; TREAGUST, David. A predict-observe-explain teaching sequence for learning about students' understanding of heat and expansion of liquids. Australian Science Teachers' Journal, v. 41, n. 1, p. 68-71, 1995.

MENESES, Fábia Maria Gomes; NUÑEZ, Isauro Beltrán. Erros e dificuldades de aprendizagem de estudantes do ensino médio na interpretação da reação química como um sistema complexo. Ciência \& Educação, Bauru, v. 24, n. 1, p. 175-190, 2018. Disponível em: https://doi.org/10.1590/1516-731320180010012. Acesso em: 22 jul. 2021.

MENEZES, Jean Michel dos Santos; FARIAS, Sidilene Aquino. Desenvolvendo a argumentação e mobilizando conceitos químicos por meio da atividade experimental investigativa. Revista Virtual de Química, v. 12, n. 1, 2020. Disponível em: http://rvqsub.sbq.org.br/index.php/rvq/article/view/3226. Acesso em: 22 jul. 2021.

MONTEIRO, Paula Cavalcante; BATISTA, Michel Corci; RODRIGUES, Maria Aparecida; FILHO, Ourides Santin. Ácidos e bases no cotidiano: uma proposta de experimento investigativo para o ensino médio. Revista Prática Docente, v. 4, n. 1, p. 227-241, 2019. Disponível em: http://periodicos.cfs.ifmt.edu.br/periodicos/index.php/rpd/article/view/408. Acesso em: 22 jul. 2021.

NASRI, Nurfaradilla Mohamad. The effectiveness of predict-observe-explain-animation (POE-A) strategy to overcome students' misconceptions about electric circuits concepts.

Learning Science and Mathematics, v. 15, p. 1-15, 2020. Disponível em: http://myjms.mohe.gov.my/index.php/lsm/article/view/9457. Acesso em: 22 jul. 2021.

NGUYEN, Joseph; KEUSEMAN, Kristopher. Chemistry in the kitchen laboratories at home. Journal of Chemical Education, v. 97, n. 9, p. 3.042-3.047, 2020. Disponível em: https://doi.org/10.1021/acs.jchemed.0c00626. Acesso em: 22 jul. 2021.

PIEPER, Fernando Colomby; ANDRADE NETO, Agostinho Serrano. Evidências da emergência de drivers hiperculturais durante o aprendizado de conceitos de eletromagnetismo em alunos do Ensino Médio após a utilização de simulações computacionais. Acta Scientiae, 
v. 17, n. 3, 2015. Disponível em:

http://www.periodicos.ulbra.br/index.php/acta/article/view/1720. Acesso em: 22 jul. 2021.

PUGGIAN, Cleonice; MORAIS, Zenildo Filho Buarque; LOPES, Cristiane Vieira Nunes

Barbosa. Ensino de reações químicas em laboratório: articulando teoria e prática na formação e ação docente. Investigações em Ensino de Ciências, v. 17, n. 3, p. 697-708, 2016.

Disponível em: https://www.if.ufrgs.br/cref/ojs/index.php/ienci/article/view/183/123. Acesso em: 12 dez. 2021.

SOUZA, Fábio Luiz; AKAHOSHI, Luciane Hiromi; MARCONDES, Maria Eunice Ribeiro; CARMO, Miriam Possar. Atividades experimentais investigativas no ensino de química. São Paulo: EDUSP, 2013.

SUART, Rita de Cássia; MARCONDES, Maria Eunice Ribeiro. A manifestação de habilidades cognitivas em atividades experimentais investigativas no Ensino Médio de química. Ciências \& Cognição, v. 14, n. 1, p. 50-74, 2009. Disponível em: http://www.cienciasecognicao.org/revista/index.php/cec/article/view/38/30. Acesso em: 12 dez. 2021.

TAKAHASHI, Eduardo Kojy; CARDOSO, Dayane Carvalho. Experimentação remota em atividades de ensino formal: um estudo a partir de periódicos Qualis A. Revista Brasileira de Pesquisa em Educação em Ciências, v. 11, n. 3, p. 185-208, 2011. Disponível em: https://periodicos.ufmg.br/index.php/rbpec/article/view/4214. Acesso em: 22 jul. 2021.

TIGAA, Rodney; SONAWANE, Swapnil. An international perspective: teaching chemistry and engaging students during the Covid-19 pandemic. Journal of Chemical Education, v. 97, n. 9, p. 3.318-3.321, 2020. Disponível em: https://doi.org/10.1021/acs.jchemed.0c00554. Acesso em: 22 jul. 2021.

VASCONCELLOS, Isadora Lopes Barbosa; TAMARIZ, Annabell Del Real; BATISTA, Silvia Cristina Freitas. Planejamento, desenvolvimento e avaliação de um ambiente virtual de aprendizagem gamificado. Renote, v. 17, n. 1, p. 21-30, 2019. Disponível em: https://doi.org/10.22456/1679-1916.95663. Acesso em: 22 jul. 2021.

WHITE, Richard; GUNSTONE, Richard. Probing understanding. London: Routledge, 2014.

YAMAGUCHI, Klenicy Kazumy de Lima. Ensino de química inorgânica mediada pelo uso das tecnologias digitais no período de ensino remoto. Revista Prática Docente, v. 6, n. 2, p. e041, 2021. Disponível em: https://doi.org/10.23926/RPD.2021.v6.n2.e041.id998. Acesso em: 22 jul. 2021. 